\title{
A.|Media Farmasi \\ UJI POTENSI ANTIMIKROBA HASIL FRAKSINASI EKSTRAK DAUN KECOMBRANG (Etlingera elatior) TERHADAP Candida albicans PENYEBAB KEPUTIHAN PADA IBU HAMIL
}

\author{
St. Ratnah ${ }^{1}$, Alfrida Monica Salasa ${ }^{2}$, H. Ismail Ibrahim ${ }^{3}$ \\ 1,2,3 Jurusan Farmasi Poltekkes Kemenkes Makassar \\ *) email : alfrida.monica@ poltekkes-mks.ac.id, no Hp.081342962441
}

https://doi.org/10.32382/mf.v14i2.595

Tanaman Kecombrang memiliki kandungan kimia seperti alkaloid, flavonoid, polifenol,steroid, saponin, dan minyak atsiri, dimana kandungan kimia tersebut dapat berperan dalam pencegahan penyakit. Tujuan dari penelitian ini adalah untuk menentukan potensi antimikroba hasil fraksinasi ekstrak daun kecombrang terhadap Candida albicans penyebab keputihan pada ibu hamil. Penelitian ini merupakan eksperimen murni menggunakan ekstrak daun kecombrang, diisolasi menggunakan kromatografi kolom sehingga diperoleh fraksi-fraksi. Hasil fraksinasi selanjutnya diuji potensi antimikrobanya terhadap Candida albicans penyebab keputihan pada ibu hamil. Zona hambat yang diperoleh diukur untuk menentukan potensi antimikroba hasil fraksinasi ekstrak Daun Kecombrang tersebut. Hasil penelitian Daun Kecombrang (Etlingera elatior), dapat disimpulkan bahwa isolasi senyawa kimia ekstrak etanol Daun Kecombrang (Etlingera elatior) diperoleh 3 senyawa murni. Ketiga senyawa murni tersebut dapat menghambat Candida albicans, rata-rata diameter zona hambat dari senyawa $A=13,66 \mathrm{~mm}$, senyawa $C=10,40 \mathrm{~mm}$ dan senyawa $E=9,33 \mathrm{~mm}$. Hasil statistik one way anava menunjukkan bahwa fraksi A (F.A) memiliki potensi antimikroba yang berbeda dengan fraksi C (F.C) dan Fraksi E (F.E) (sig p < 0,05) sedangkan fraksi C (F.C) dan Fraksi E (F.E) memiliki potensi antimikroba yang sama (sig $\mathrm{p}>0,05)$.

\section{Kata kunci : Ekstrak Daun Kecombrang, Hasil Fraksinasi, Aktivitas antimikroba, Candida albicans}

\section{PENDAHULUAN}

Keputihan sering terjadi pada ibu hamil, hal ini disebabkan oleh banyak faktor diantaranya karena perubahan hormon yang menyebabkan meningkatnya produksi keringat sehingga kelembaban daerah kewanitaan meningkat. Dengan demikian pH normal daerah kewanitaan berubah sehingga terjadi keputihan.

Keputihan disebabkan oleh infeksi mikroorganisme. Penyebab utamanya adalah Candida albicans. Keputihan dapat diatasi dengan pemberian antimikroba baik secara oral maupun digunakan sebagai obat luar. Pemberian antimikroba pada ibu hamil harus betul-betul diperhatikan karena dapat mengganggu perkembangan dari janin.Salah satu tanaman yang dapat digunakan sebagai obat tradisional tersebut adalah Kecombrang (Etlingera elatior).

Kecombrang merupakan salah satu jenis tanaman rempah - rempah asli Indonesia yang termasuk dalam famili Zingiberaceae, masyarakat di daerah Luwu menggunakan Buah Kecombrang sebagai bumbu masak, juga secara tradisional digunakan sebagai obat-obatan. Beberapa tahun terakhir ini, tanaman Kecombrang mendapat perhatian sangat besar karena adanya fakta empiris serta bukti penelitian ilmiah, Bunga Kecombrang memiliki kandungan kimia seperti alkaloid, flavonoid, polifenol,steroid, saponin, dan minyak atsiri. Kandungan senyawa fitokimia pada tanaman diketahui mempunyai peranan yang sangat penting bagi kesehatan termasuk fungsinya dalam pencegahan terhadap penyakit (Tampubolon et al., 1983; Winarti dan Nurdjanah, 2005). Penelitian terhadap Bunga dan Buah Kecombrang telah dilakukan oleh Habsah et al. (2005) bahwa Kecombrang dapat dipakai untuk mengobati beberapa penyakit infeksi dan penyakit degenerative seperti kanker dan tumor. Menurut Hudaya, (2010) dan Akbar (2008) Kecombrang memiliki aktivitas antibakteri dan antioksidan (Muawanah, A., et al, 2012). Selain itu Kecombrang sebagai penghilang bau badan (Sirait. N., 2008). Menurut Jafar et al., (2007) Kecombrang mengandung minyak esensial yang bersifat bioaktif (daun 0,0735\%; bunga 0,0334\%; batang $0,0029 \%$ dan rhizome $0,0021 \%$ ). Menurut Naufalin et al., (2005) zat antibakteri dari ekstrak etanol dan etil asetat dari bunga Kecombrang dapat menghambat berbagai bakteri seperti 
Bacillus cereus, P. aeroginosa, S. typhimurium, dan Eschericia coli.

Pada penelitian hibah tahun 2016 yang dilakukan oleh Ismail dkk menunjukkan bahwa Ekstrak etanol, ekstrak dietil eter, dan ekstrak nbutanol Daun kecombrang dapat menghambat pertumbuhan Escherichia coli dan Candida albicans. Penelitian ini merupakan lanjutan dari penelitian sebelumnya tentang uji aktifitas isolat daun kecombrang terhadap Candida albicans dan Streptococcus mutans. Pada penelitian ini akan dilakukan uji potensi antimikroba hasil fraksinasi ekstrak daun kecombrang terhadap Candida albicans penyebab keputihan pada ibu hamil.

Berdasarkan uraian di atas, maka rumusan masalah dalam penelitian ini adalah bagaimana potensi antimikroba hasil fraksinasi ekstrak daun kecombrang terhadap Candida albicans penyebab keputihan pada ibu hamil?

Tujuan dari penelitian ini adalah untuk menentukan potensi antimikroba hasil fraksinasi ektrak daun kecombrang terhadap Candida albicans penyebab keputihan pada ibu hamil

\section{METODE}

\section{Desain, tempat dan waktu}

Jenis penelitian yang digunakan adalah penelitian eksperimental dengan melakukan fraksinasi ekstrak daun kecombrang dan dilanjutkan dengan uji potensi antimikroba terhadap Candida albicans penyebab keputihan pada ibu hamil. Penelitian ini telah dilakukan pada Tahun Mei - Oktober 2017, di Laboratorium Biologi Farmasi Jurusan Farmasi Politeknik Kesehatan Kemenkes RI Makassar.

\section{Bahan dan alat}

Bahan uji pada penelitian ini adalah daun Kecombrang dan sampel penelitian adalah Candida albicans. Alat yang digunakan adalah Alat - Alat yang digunakan ; Autoklaf, Inkubator, LAF (Laminar Air Flow), Oven, Lampu UV 254 $\mathrm{nm}$, Rotavapor, penangas air, Cawan Porselin, Cawan Petri, Erlenmeyer, Gelas piala, Gelas ukur, Ose, Kertas saring, Plat Kaca, Seperangkat alat kromatografi kolom, Timbangan elektrik. Bahan bahan yang digunakan ; Aluminium foil, paper disk, Etanol $96 \%$, Etil asetat p.a, Heksan p.a, Larutan $\mathrm{NaCl}$ 0,9 \%, Media Sabaroud Dextrose Agar, Silika gel, Candida albicans, Ekstrak Daun Kecombrang (Etlingera elatior).

\section{Prosedur Penelitian}

Daun kecombrang yang telah dipotongpotong dan dikeringkan diekstraksi dengan metode maserasi dengan menggunakan pelarut etanol 96\% lalu diuapkan hingga dipeoleh ekstrak kental. Ekstrak kental yang diperoleh selanjutnya difraksinasi dengan menggunakan kromatografi kolom dengan menggunakan eluen heksan : etil asetat dengan perbandingan 9:1 dan 8:2. Isolat yang diperoleh ditampung dalam vial. Selanjutnya isolat yang diperoleh diuji potensi antimikrobanya terhadap Candida albicans penyebab keputihan pada ibu hamil dengan menggunakan metode difusi agar. Diamati zona hambat yang terbentuk dan diukur diameter zona hambatnya

\section{Pengolahan dan analisis data}

Setelah 24 jam inkubasi, diameter zona hambat yang terbentuk diukur dengan menggunakan jangka sorong

\section{HASIL}

Hasil identifikasi dengan metode kromatografi lapis tipis Ekstrak etanol Daun kecobrang dengan cairan pengelusi Heksan:Etil asetat (8:2) dengan penampak noda sinar UV 254 $\mathrm{nm}$ diperoleh 7 noda. Hasil isolasi dengan metode Kromatografi Kolom Ekstrak Daun Kecombrang dengan cairan pengelusi Heksan : Etil asetat (9:1, $8: 2$, 7:3, dan 6:4) diperoleh 3 isolat senyawa tunggal yaitu: Fraksi A, fraksi C dan fraksi E. Hasil uji antimikroba terhadap Candida albicans diperoleh diameter zona hambat fraksi A 13,66 $\mathrm{mm}$; fraksi C sebesar 10,4 $\mathrm{mm}$ dan fraksi C sebesar $9,33 \mathrm{~mm}$.

\section{PEMBAHASAN}

Bahan uji pada penelitian ini adalah Daun Kecombrang (Etlingera elatior) dari daerah Masamba Kabupaten Luwu Utara. Daun segar dipetik pada pagi hari, helaian daun yang masih utuh, berada pada urutan 3-5 dari pucuk, dicuci bersih dengan air mengalir, dipotong kecil-kecil, kemudian dikering-anginkan, selanjutnya disebut sebagai simplisia. Simplisa tersebut diekstraksi dengan metode maserasi, lalu ekstrak cair yang diperoleh dipekatkan hingga diperoleh ekstrak kental.

Ekstrak kering ditimbang 5,0 g kemudian dilarutkan dengan $10 \mathrm{ml}$ campuran pelarut Heksan - Etil Asetat (5 : 5), Percampuran kedua macam pelarut ini dibuat pula dengan kombinasi yang bervariasi, yang selanjutnya larutan ini disebut sebagai eluen, pada metode kromatografi kolom 
biasa disebut cairan pembilas. Eluen yang digunakan pada proses pemisahan atau isolasi senyawa kimia pada ekstrak dengan kromatografi kolom, dibuat dengan kombinasi campuran pelarut Heksan - Etil Asetat (9:1), Heksan - Etil Asetat (8:2), dan Heksan - Etil Asetat (7:3).

Pemisahan atau isolasi senyawa kimia dengan metode Kromatografi Kolom menggunakan adsorben Silika gel (Kieselgel 60 (0,2 - 0,5 mm) Merck.) Ekstrak yang telah dilarutkan dengan eluen dimasukkan ke dalam kolom yang sebelumnya telah diisi dengan Kieselgel dan cairan pembilas (eluen) Heksan Etil Asetat (9:1). Selanjutnya dielusi hingga senyawa kimia tersebut terpisah atau terpartisi dalam kolom, laju aliran dalam kolom diupayakan perlahan-lahan, tetesan cairan pembilas yang berisi senyawa terlarut yang keluar secara perlahan dari mulut kolom kira-kira 2-3 tetes dalam 1 menit, kemudian ditampung dalam wadah botol kecil (vial) setiap $5 \mathrm{ml}$, yang selanjutnya disebut sebagai fraksi-fraksi. Untuk memisahkan atau mempartisi setiap senyawa dalam ekstrak yang memiliki kelarutan yang berbeda-beda, maka eluen diganti secara berurutan berdasarkan tingkat kepolarannya, yaitu berurutan mulai dari eluen Heksan - Etil Asetat ( 9 : 1) selanjutnya dengan eluen Heksan - Etil Asetat (8:2) dan terakhir Heksan - Etil Asetat (7:3), dengan demikian maka senyawa kimia mengalami partisi atau pemisahan antar senyawa kimia dalam ekstrak tersebut. Partisi terjadi berdasarkan sifat kepolaran senyawa yang mengakibatkan perbedaan kelarutan masing-masing senyawa kimia dalam eluen, sehingga senyawa yang keluar dari kolom kromatografi terpisah satu per satu atau terisolasi, yang selanjutnya dinyatakan sebagai isolat. Isolat tidak semuanya merupakan senyawa murni, namun beberapa fraksi masih tergabung 2 atau 3 senyawa. Fraksi yang diperoleh hingga akhir proses isolasi sebanyak 100 vial botol, kemudian disatukan menjadi 6 kelompok, selanjutnya disebut sebagai Fraksi A (F.A), Fraksi B (F.B), Fraksi C (F.C) dan Fraksi E (F.E) dan Fraksi F (F.F).

Penentuan isolat sebagai senyawa murni dilakukan dengan cara mengidentifikasi masingmasing fraksi dengan kromatografi lapis tipis (TLC Silica gel 60 F254, Merck), fraksi-fraksi yang menunjukkan satu noda yang sama, disatukan atau digabung kembali yang selanjutnya dinyatakan sebagai senyawa murni. Untuk membuktikan bahwa fraksi gabungan tersebut benar-benar merupakan senyawa murni, maka dilakukan uji dengan kromatografi lapis tipis dua arah, yaitu dielusi dua kali dengan eluen arah pertama berbeda dengan eluen arah kedua. Pada penelitian ini diperoleh 3 fraksi yang dapat dinyatakan sebagai senyawa murni dan diberi nama sebagai Fraksi A (F.A), Fraksi C (F.C) dan Fraksi E (F.E).

Uji aktivitas antibakteri dari Fraksi A (F.A), Fraksi C (F.C) dan Fraksi E (F.E) terhadap Candida albicans, dilakukan dengan cara masingmasing fraksi diserap dengan Kertas serap disk (Susceptibility Discs 6mm, Blank Discs, Oxoid). Kertas serap disk dimasukkan ke dalam masingmasing fraksi murni, didiamkan selama 10 menit, dikeluarkan dan dikering-anginkan. Selanjutnya ketiga kertas serap disk tersebut diletakkan ke dalam cawan petri yang telah diinokulasikan Candida albicans pada media SDA (Sabouraud Dextrose Agar, Merck), kemudian diinkubasi selama 2 × 24 jam pada suhu $25^{\circ} \mathrm{C}$, perlakuan dengan tiga replikasi.

Data hasil pengamatan aktivitas antimikroba dari ketiga senyawa tersebut diperoleh dengan pengukuran diameter zona bening, yaitu daerah yang tidak terjadi pertumbuhan mikroorganisme karena adanya daya aktivitas dari suatu senyawa, sehingga daerah disekeliling senyawa tersebut tidak mengalami pertumbuhan mikroorganisme. Data hasil pengukuran diameter zona bening, yaitu pada cawan petri $\mathrm{I}$, diperoleh diameter zona hambat untuk Fraksi $\mathrm{A}=14,4 \mathrm{~mm}$, Fraksi $\mathrm{C}=$ $11,2 \mathrm{~mm}$ dan Fraksi $\mathrm{E}=10,0 \mathrm{~mm}$. Pada cawan petri II, diperoleh diameter zona hambat untuk Fraksi $\mathrm{A}=13,6 \mathrm{~mm}$, Fraksi $\mathrm{C}=10,4 \mathrm{~mm}$ dan Fraksi $\mathrm{E}=9,6 \mathrm{~mm}$. Sedang pada cawan petri III, diperoleh diameter zona hambat untuk Fraksi $\mathrm{A}=$ 13,0 mm, Fraksi $\mathrm{C}=9,6 \mathrm{~mm}$ dan Fraksi $\mathrm{E}=8,4$ $\mathrm{mm}$. Sehingga dapat dinyatakan bahwa rata-rata diameter zona hambat terhadap Candida albicans, pada Fraksi A (F.A) atau Senyawa A = 13,66 mm, Fraksi C (F.C) atau Senyawa C $=10,40 \mathrm{~mm}$ dan Fraksi $\mathrm{E}$ atau Senyawa $\mathrm{E}=9,33 \mathrm{~mm}$.

Hasil statistik one way anava menunjukkan bahwa fraksi A (F.A) memiliki potensi antimikroba yang berbeda dengan fraksi C (F.C) dan Fraksi E (F.E) (sig p < 0,05) sedangkan fraksi C (F.C) dan Fraksi E (F.E) memiliki potensi antimikroba yang sama (sig $\mathrm{p}>0,05)$.

\section{KESIMPULAN}

Berdasarkan hasil penelitian dan analisis data yang diperoleh dapat disimpulkan bahwa hasil fraksinasi Ekstrak Daun Kecombrang 
(Etlingera elatior) memiliki potensi antimikroba terhadap Candida albicans penyebab keputihan pada ibu hamil.

\section{SARAN}

Penelitian ini dapat dilanjutkan untuk melihat potensi antimikroba hasil fraksinasi ekstrak Daun kecombrang terhadap bakteri penyebab penyakit.

\section{DAFTAR PUSTAKA}

Akbar, J. 2008. Pemanfaatan Ekstrak Bunga Kecombrang (Nicolaia speciosa Horan) Terhadap Penyembuhan Infeksi Jamur Saprolegnia sp Pada Ikan Nila Merah.Jurnal Kalimantan Scientiae. Vol. XXVI (71) : 32-38.

Atlas, R.,1990. Hand Book of Microbiological Media. Edited by Parks, L.C., Boca Raton. United State of America, hal 666,672 .

Direktorat Jenderal Pengawasan Obat Dan Makanan. 1986. Sediaan Galenik Departemen Kesehatan RI. Jakarta. Hal; 19.

Djide, M. N. 2006. Mikrobiologi Farmasi. Jurusan Farmasi UNHAS, Makassar.

Dwiatmini, K., et al. 2009. Induksi Mutasi Kecombrang (Etlingera elatior) Menggunakan Iradiasi Sinar Gamma. Journal Hortikultura. Vol. 19 No. 1. Hal: $1-5$.

Gritter, R.J., Bobbit, J.M., dan Schwarting, A.E., 1991, Pengantar Kromatografi Ed.2 terjemahan Padmawinata.

Jewetz, E., 1986, Mikrobiologi Untuk Profesi Kesehatan Jilid II, Terjemahan Badan Litbang Kesehatan, Jakarta.

Jaffar F. M., C. P.Osman,. N.H. Ismail, and K. Awang. 2007. Analysis of Essential oils of leaves, stems, flowers, and Rhizomes of Etlingera elatior (JACK) R.M. SMITH. The Malaysian Journal of Analytical Scienses, Vol.11, Hal: 269273.

Leslie B et al., 2010, Microbiology, USA, Pearson Education
Moaiedmohsen S. et al, Cervicovaginal infection During Third Trimester of Pregnancy, Journal Of Family and Reproductive Health

Muawanah, A., et al., 2012. Penggunaan Bunga Kecombrang (Etlingera elatior) dalam Proses Fermentasi Permen Jelly. Jurnal Valensi Vol. 2 No. 4, Mei 2012 (526533). ISSN : $1978-8193$.

Naufalin. R., 2005. Kajian Sifat Antimkiroba Ekstrak Bunga Kecombrang (Nicolaia speciosa Horan) terhadap berbagai mikroba Patogen dan Perusak Pangan. Disertasi. Pascasarjana Institut Pertanian Bogor.

Niemi, A., 2009. Culinary Application of Torch Ginger Etlingera elatior. Bulletin Heliconia Society International. Vol.15 No. 3, Hal 11.

Padmawinata, K. 1995. Cara Kromatografi Preparative Penggunaan Pada Isolasi Senyawa Alam. Penerbit ITB. Bandung.

Sirait. N., 2008. Penggunaan Berbagai Jenis tanaman Obat untuk menanggulangi Bau Badan. Journal WARTA Penelitian dan Pengembangan Tanaman Industri Vol. 14 (3) Hal: 8-9.

Stahl, E. 1985. Analisis Obat Secara Kromatografi dan Mikroskopi. Penerbit ITB. Bandung.

Sudjaji. 1988. Metode Pemisahan. Penerbit Kanisius. Yogyakarta.

Tampubolon, O.T., S. Suhatsyah dan S.Sastrapradja. 1983. Penelitian Pendahuluan Kandungan Kimia Kecombrang (Nicolaia Speciosa Horan) dalam Risalah Simposium Penelitian Tumbuhan Obat III. Fakultas Farmasi UGM. DIY. Hal: 451-454.

Wijayakusuma, H.M.H., 1999, Tanaman Berkhasiat Obat Di Indonesia, Jilid I, Prestasi Insan Indonesia, Jakarta. 8-15.

Winarti, C dan Nurdjanah, N. 2005.Peluang Tanaman Rempah dan Obat Sebagai Sumber Pangan Fungsional. Jurnal Litbang Pertanian. Vol. 24(2) : 47-55. 
Tabel 1

Hasil identifikasi dengan metode Kromatografi LapisTipis Ekstrak Etanol Daun Kecombrang Dengan Cairan Pengelusi Heksan : Etil Asetat $(8: 2)$, penampak noda Sinar UV 254

\begin{tabular}{ccc}
\hline NO & WARNA NODA & NILAI Rf \\
\hline 1 & Kuning & 0,91 \\
2 & Ungu & 0,63 \\
3 & Hijau tua & 0,58 \\
4 & Hijau tua & 0,41 \\
5 & Hijau muda & 0,35 \\
6 & Kuning & 0,25 \\
\hline
\end{tabular}

Tabel 2

Hasil Isolasi dengan metode Kromatografi Kolom Ekstrak Daun Kecombrang Dengan Cairan Pengelusi Heksan - Etil Asetat (9:1, $8: 2$, dan $7: 3$ )

\begin{tabular}{cccc}
\hline NO & Nomor Fraksi & Nama Fraksi & $\begin{array}{c}\text { Jumlah Noda } \\
\text { (Senyawa Kimia) }\end{array}$ \\
\hline 1 & $1-15$ & F 1 & 1 \\
2 & $16-29$ & F 2 & 3 \\
3 & $30-38$ & F 3 & 1 \\
4 & $39-44$ & F 4 & 2 \\
5 & $45-64$ & F 5 & 1 \\
6 & $65-100$ & F 6 & 3 \\
\hline
\end{tabular}


Tabel 3

Hasil Uji Aktivitas Antimikroba Fraksi A (F.A), Fraksi C (F.C) dan Fraksi E (F.E) terhadap Candida albicans

\begin{tabular}{|c|c|c|c|c|}
\hline \multirow[t]{2}{*}{ No } & \multirow[t]{2}{*}{ Hasil Isolat } & \multicolumn{2}{|c|}{$\begin{array}{c}\text { Perlakuan/Diameter Zona } \\
\text { Hambat (mm) }\end{array}$} & \multirow[t]{2}{*}{$\begin{array}{c}\text { Diameter Zona Hambat } \\
\text { Rata-Rata }(\mathrm{mm})\end{array}$} \\
\hline & & 1 & 14,4 & \\
\hline \multirow[t]{3}{*}{1} & F.A & 2 & 13,6 & 13,66 \\
\hline & & 3 & 13,0 & \\
\hline & & 1 & 11,2 & \\
\hline \multirow[t]{3}{*}{2} & F.C & 2 & 10,4 & 10,40 \\
\hline & & 3 & 9,6 & \\
\hline & & 1 & 10,0 & \\
\hline \multirow[t]{2}{*}{3} & F.E & 2 & 9,6 & 9,33 \\
\hline & & 3 & 8,4 & \\
\hline
\end{tabular}




\section{MEDIA FARMASI}

POLITEKNIK KESEHATAN MAKASSAR

Penasehat

Penanggung Jawab

Dewan Redaksi

Ketua

Anggota

Mitra Bestari

Alamat Redaksi
: Direktur Politeknik Kesehatan Kemenkes Makassar

: Ketua Jurusan Farmasi Politeknik Kesehatan

Kemenkes Makassar

: $\quad$ Santi Sinala, S,Si, M.Si, Apt

: Hendra Stevani, S.Si, M.Kes, Apt

Sisilia Teresia Rosmala Dewi, S.Si, M.Kes, Apt

Muli Sukmawaty, S.Farm, Apt

Muhammad Riswan, S.Kom

: $\quad$ Dr. Islamudin Ahmad, M.Si,Apt (Universitas Mulawarman)

DR. Rusli, Sp.FRS, Apt

DR. Hj. Nurisyah, M.Si, Apt (Poltekkes Makassar)

DR. Sesilia Rante Pakadang, M.Si, Apt (Poltekkes Makassar)

DR. H. Asyhari Asyikin, S.Farm, M.Kes (Poltekkes Makassar)

: Jurusan Farmasi

Politeknik Kesehatan Kementerian Kesehatan Makassar

J1. Baji Gau No.10 Makassar

Telp. 0411-854021, 830883 Fax. 0411-830883

Kode pos 90134

Website :

http://journal.poltekkes-mks.ac.id/ojs2/index.php/mediafarmasi/index 


\section{EDITORIAL}

Pembaca yang budiman, ucapan syukur Alhamdulillah kami panjatkan ke hadirat Tuhan Yang Maha Kuasa karena berkat rahmat dan anugerahNya sehingga penerbitan Vol. XIV No.2, Oktober 2018 MEDIA FARMASI POLITEKNIK KESEHATAN MAKASSAR dapat terlaksana dan telah mendapat legalitas sebagai media resmi dari Lembaga Ilmu Pengetahuan Indonesia (LIPI) dengan nomor penerbitan pISSN No. 0216-2083 dan e-ISSN No. 2622-0962.

Media Farmasi Politeknik Kesehatan Makassar merupakan suatu wadah dalam menampung aspirasi ilmiah sehingga dapat menggugah motivasi dan inovasi dari dosen di lingkup Jurusan Farmasi Politeknik Kesehatan Makassar serta artikel dari simpatisan untuk melakukan kajian ilmiah.

Media Farmasi Politeknik Kesehatan Makassar diterbitkan 2 kali dalam setahun yaitu pada bulan April dan Oktober. Sebagai majalah ilmiah, Media Farmasi mengembangkan misi dalam memajukan ilmu pengetahuan dan teknologi kesehatan khususnya di bidang farmasi

Akhirnya redaksi sangat berharap bahwa semua artikel yang disajikan dalam edisi ini dapat memberi apresiasi keilmuan di bidang kesehatan bagi kita semua. Oleh karena itu kritikan dan saran sangat kami harapkan demi kesempurnaan edisi-edisi selanjutnya.

Selamat membaca

Makassar, Oktober 2018

Redaksi 


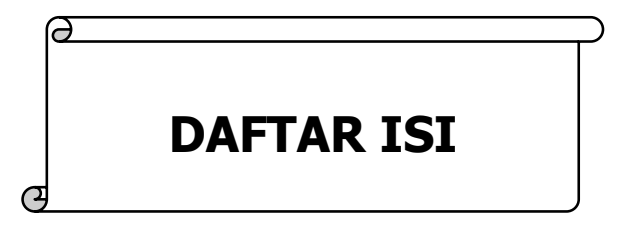

Pengaruh Pemberian Ekstrak Etanol Daun Afrika (Vernonia amygdalina

Del.) terhadap Kadar Asam Urat Darah Mencit Jantan (Mus musculus)

Jumain, Asmawati, Rini Karnita

Efektivitas Pemberian Rebusan Daun Pandan Wangi (Pandanus

Amaryllifolius Roxb.) terhadap Penurunan Kadar Glukosa Darah

Mencit (Mus musculus)

Amran Nur, Desi Reski Fajar, Musdalifah

Uji Efek Analgetik Infusa Jahe (Zingiber officinale Roscoe) terhadap Hewan Uji Mencit Jantan (Mus musculus)

Sisilia T. Rosmala Dewi, Hiany Salim.

Pengaruh Usia dan Tingkat Pendidikan terhadap Pemahaman Pasien

Setelah Pelayanan Informasi Obat di Puskesmas Makale Kabupaten

Tana Toraja Tahun 2018

Estherina Allo Payung, Septyani Mambela

Uji Daya Hambat Antibiotika Terhadap Bakteri Penyebab Infeksi

Saluran Kemih Di Rumah Sakit Salewangang Maros

Andi Dian Aulia Saudi, Rusdy

Uji Aktivitas Ekstrak Buah Pare (Momordica charantia L) terhadap Pertumbuhan Propionibacterium acnes

Dwi Rachmawaty Daswi, Asmawati

Analisis Kandungan Merkuri (Hg) pada Sediaan Krim Pemutih yang Beredar di Pasaran Kota Makassar dengan Menggunakan Metode Spektrofotometri Serapan Atom

Dedy Ma'ruf, Andi Asmawati, Ririn Muliana

Penentuan Total Polifenol Ekstrak Etanol Kulit Kecapi (Sandoricum koetjape) dari Lamasi Kabupaten Luwu

Santi Sinala, Minati, Alfrida Monica Salasa

Uji Potensi Antimikroba Hasil Fraksinasi Ekstrak Daun Kecombrang (Etlingera elatior) terhadap Candida albicans Penyebab Keputihan Pada Ibu Hamil

St. Ratnah, Alfrida Monica Salasa, H. Ismail Ibrahim 
Efek Konseling terhadap Tingkat Pengetahuan Ibu pada Terapi

Diare Balita

Khaerani, Surya Ningsi, Andi Try Resti Fauziah Sahib

Uji Daya Hambat Daun Tammate (Lannea coromandelica) terhadap

Bakteri Propionibacterium acnes dan Escherichia coli

Nurlaela, Abd.Karim, Taufiq Dalming

Efektivitas Ekstrak Air Buah Belimbing Wuluh (Averrhoa bilimbi)

Terhadap Pertumbuhan Propionibacterium acnes

Arisanty, Rara Puspa Dewi

Aktivitas Perasan Biji Pinang (Areca catechu L.) terhadap Pertumbuhan

Streptococcus mutans

Ikke Nurjanna, Hendra Stevani, Ratnasari Dewi

Evaluasi Tingkat Kepuasaan Pasien terhadap Pelayanan Kefarmasin di Depo IGD

Rumah Sakit TK II Pelamonia Makassar

Rahmawati, Desi Reski Fajar, Ira Widya Sari

78

Analisis Lama Waktu Tunggu Pelayanan Resep di Apotek BPJS

Rawat Jalan Rumah Sakit Pelamonia

Veronika Dampung, Ita Purnama Sari, Citra Rahayu, Rusli 